Bull. Mater. Sci., Vol. 36, No. 7, December 2013, pp. 1291-1295. (C) Indian Academy of Sciences.

\title{
Influence of Al content on textural properties and catalytic activity of hierarchical porous aluminosilicate materials
}

\author{
LING XU, LIMEI DUAN, ZONGRUI LIU, JINGQI GUAN ${ }^{\dagger}, *$ and QIUBIN KAN $\mathbf{N}^{\dagger, *}$ \\ College of Chemistry and Chemical Engineering, Inner Mongolia University for Nationalities, Tongliao 028000, China \\ ${ }^{\dagger}$ College of Chemistry, Jilin University, Changchun 130023, China
}

MS received 10 July 2012; revised 9 September 2012

\begin{abstract}
A series of hierarchical porous aluminosilicate materials were prepared using hydrothermal treatment of the composite formed by polystyrene colloidal spheres and aluminosilicate gel. Influence of Al content on the textural properties, acidic properties and catalytic activity of the hierarchical porous aluminosilicate materials was studied. The results showed that textural and acidic properties of the hierarchical porous aluminosilicate materials were strongly related to Al content. As Al content is increased $\left(n_{\mathrm{Si}} / n_{\mathrm{Al}}=25\right)$, the hierarchical porous catalysts exhibited higher catalytic activity and major product selectivity for alkylation of phenol with tert-butanol than the catalysts with a lower Al content $\left(n_{\mathrm{Si}} / n_{\mathrm{Al}}=\mathbf{5 0}\right)$.
\end{abstract}

Keywords. Hierarchical ZSM-5 zeolite catalyst; alkylation; phenol; tert-butyl alcohol.

\section{Introduction}

It is well known that hierarchical porous materials have received much attention due to the benefits of multiple poresize regimes (Yuan and Su 2006; Holma et al 2011). Generally, the hierarchical porous aluminosilicate materials are widely used in heterogeneous catalysis areas (Shetti et al 2008; Sun and Prins 2008; Serrano et al 2011). The high surface area provides abundant active sites to improve the catalytic activity and the hierarchical porous systems have already been proven to be beneficial for the mass transportation of substrates and products. Various smart strategies have been developed to prepare the hierarchical porous materials. Conventionally, hierarchical zeolites with macropores and/or mesopores were obtained by the construction of zeolite nanocrystals using different methods. Some methods include semi-zeolitic transformation of porous amorphous silica materials and recrystallization of self-assembling zeolite seeds templated by polystyrene spheres. For example, Valtchev (2002) employed hydrothermal treatment of monodisperse polystyrene spheres and silicalite-1 nanocrystals to obtain a macroporous material composed of silicalite-1 nanocrystals (Valtchev 2002). Wang et al (2000) and Zhu et al (2001) provided a method of preparation for micromacroporous materials through the infiltration of nanocrystals into an ordered array of polystyrene spheres (Wang et al

\footnotetext{
*Author for correspondence (guanjq@jlu.edu.cn,
} qkan@mail.jlu.edu.cn)
2000; Zhu et al 2001). Recently, Huang et al (2010) suggested a strategy for preparing the hierarchical porous zeolite NaY. It is worth noting that, the porosity of zeolite $\mathrm{NaY}$ can be controlled by varying the water/silica molar ratio of the synthesis gel (Huang et al 2010). Takahashi et al (2001) reported the silica-alumina catalysts with continuous macropores and mesopores through phase separation and sol-gel process (Takahashi et al 2001). The catalysts showed higher catalytic activity than that of commercial silica-alumina catalysts in cracking of cumene and dehydrating 2-propanol. Additionally, Lei et al (2006) prepared a hierarchical pore-structured zeolite catalyst by transforming the skeleton of silica gel through a steam-assisted conversion method (Lei et al 2006). The catalyst showed higher catalytic activity for catalytic cracking of the large molecules of 1,3,5-triisopropyl benzene. The catalytic results clearly suggest that macropores favour the mass transfer and reduce transportation limitations.

In our preliminary work, we studied the hierarchical porous aluminosilicate materials and investigated the effect of crystallization time on the physico-chemical and catalytic properties (Xu et al 2010). The results showed that catalytic performance of the hierarchical porous aluminosilicate materials was determined by acidity and pore structures. It is well known that acidity of porous materials are a complex issue influenced by a variety of factors such as crystalline degree, Si/Al molar ratio and so on. Herein, we demonstrate the preparation, characterization and catalytic properties of hierarchical porous aluminosilicate materials with high $\mathrm{Al}$ content. In addition, we investigate the effect of increasing $\mathrm{Al}$ content in the initial gel on the textural and catalytic properties of the hierarchical porous aluminosilicate materials. 


\section{Experimental}

\subsection{Sample preparation}

To prepare the hierarchical porous aluminosilicate materials, tetraethoxysilane and aluminum sulfate were used as the silica and aluminum source, respectively. The detailed synthesis procedures were in accordance with our previous report (Xu et al 2010). The only difference was the addition of $\mathrm{Al}$ content with $\mathrm{Si} / \mathrm{Al}$ molar ratio of $25\left(n_{\mathrm{Si}} / n_{\mathrm{Al}}=25\right)$ in the initial gel. The calcined materials were denoted as C-Xh (25), where X represents the crystallization time and (25) represents $\mathrm{Si} / \mathrm{Al}$ molar ratio in the initial gel.

Lastly, the protonated form of the samples was obtained from an ion-exchange with $\mathrm{NH}_{4} \mathrm{NO}_{3}$, followed by calcination at $773 \mathrm{~K}$ for $5 \mathrm{~h}$.

\subsection{Characterization of samples}

Powder X-ray diffraction (XRD) patterns were acquired on a SHIMADZU XRD-6000 automatic diffractometer using $\mathrm{CuK} \alpha(\lambda=0.15418 \mathrm{~nm})$ radiation and operated at $40 \cdot 0 \mathrm{kV}$ and $200.0 \mathrm{~mA}$. The diffraction was carried out in the range of $(2 \theta)$ from 5 to $35^{\circ}$ at a scanning speed of $2^{\circ} / \mathrm{min}$. In addition, the crystallinity of each sample was measured between the peak area of $2 \theta=22-25^{\circ}$ using a highly crystallized ZSM-5 standard sample $(\mathrm{ZSM}-5, \mathrm{Si} / \mathrm{Al}$ molar ratio $=50$, supplied by Nankai University) as a reference.

$\mathrm{N}_{2}$ adsorption-desorption isotherms were recorded at $77 \mathrm{~K}$ using a Micromeritics ASAP 2020. Before measurements were taken, samples were outgassed at $573 \mathrm{~K}$ for $4 \mathrm{~h}$. BET surface areas were obtained from adsorption branches in a relative pressure range of $0 \cdot 05-0 \cdot 30$. Pore size distributions were calculated from adsorption branches using BarretJoyner-Halenda (BJH) method. The pore volume was taken at a relative pressure of 0.974 .

Scanning electron microscopy (SEM) experiments were performed on a Hitachi X-650 electron microscope with an acceleration voltage of $200 \mathrm{kV}$.

$\mathrm{Si} / \mathrm{Al}$ ratio of the samples was measured on a PerkinElmer Optima 3300 DV ICP instrument.

${ }^{27}$ Al-MAS NMR spectrum was determined on a Varian Unity-400 spectrometer operating with a magnetic field of $\mathrm{B}_{0}=0.94 \mathrm{~T}$, NMR frequencies of $104 \mathrm{MHz}$ and a spin rate of $10 \mathrm{kHz}$. The chemical shifts were referenced to $\mathrm{Al}\left(\mathrm{H}_{2} \mathrm{O}\right)_{6}^{3+}$.

\subsection{Catalytic test}

Alkylation of phenol with tert-butanol was carried out at atmospheric pressure in a continuously flowing fixed quartz bed reactor (i.d. $6 \mathrm{~mm}$ ) using $0.5 \mathrm{~g}$ of catalysts. Prior to catalytic reaction, the catalysts were activated in $\mathrm{N}_{2}$ at $773 \mathrm{~K}$ for $1 \mathrm{~h}$ to eliminate physically and chemically adsorbed water. Then the reactor was cooled to $418 \mathrm{~K}$ under $\mathrm{N}_{2}$ flow of $20 \mathrm{~mL} / \mathrm{min}$. The reaction mixture was injected from the top utilizing a syringe pump. The products were measured using gas chromatography (GC-8A, Shimadzu) and confirmed through gas chromatography-mass spectrometry (GC-MS).

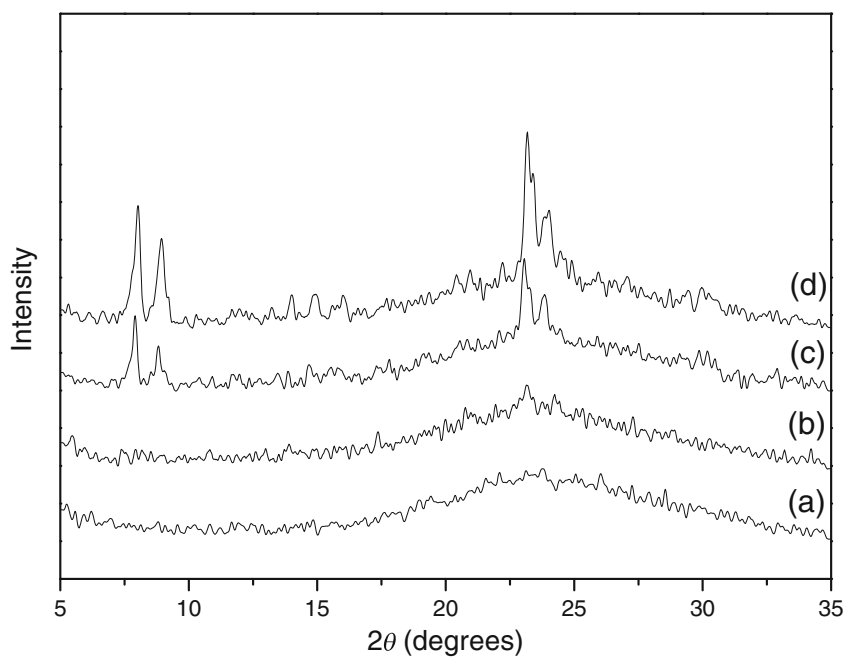

Figure 1. XRD patterns of samples: (a) C-16h (25), (b) C-22h (25), (c) C-36h (25) and (d) C-48h (25).

\section{Results and discussion}

\subsection{XRD studies}

Figure 1 shows XRD patterns of the hierarchical porous aluminosilicate materials. XRD pattern of C-16h (25) exhibits characteristic peaks indexed as amorphous structures (figure 1a). To our knowledge, when crystallization time was $16 \mathrm{~h}, \mathrm{XRD}$ pattern of the sample C-16h with $n_{\mathrm{Si}} / n_{\mathrm{Al}}=50$ exhibited the diffraction peaks assigned to MFI structure $(\mathrm{Xu}$ et al 2010). Compared to the sample of C-16h (25) obtained from a high $\mathrm{Al}$ content with the reported sample of $\mathrm{C}-16 \mathrm{~h}$ (50) obtained from a low Al content in the initial gel, we can find that crystallization rate decreases with increased $\mathrm{Al}$ content in the initial gel. The result is in good agreement with the reported literature (Song et al 1991; Persson et al 1995; Ali et al 2003). This outcome was probably due to the necessity of exchanging cations simultaneously with $\mathrm{Al}$ in the zeolite framework during the crystallization process (Persson et al 1995).

When crystallization time was $22 \mathrm{~h}$, XRD pattern of $\mathrm{C}-22 \mathrm{~h}$ (25) revealed characteristic reflections ascribed to MFI structure (figure 1b) and the intensity of XRD diffraction peaks was lower than those of C-36h (25) and C-48h (25) with a longer crystallization time, which implies a lower crystallinity in the sample C-22h (25).

\section{$3.2 \mathrm{~N}_{2}$ adsorption-desorption studies}

$\mathrm{N}_{2}$ adsorption-desorption isotherms and pore size distribution of the hierarchical porous aluminosilicate materials are shown in figure 2. The isotherms of C-16h (25), C-22h (25) and C-36h (25) exhibit type IV with H1 hysteresis loops (as shown in figure 2(a)), which indicates the presence of a mesoporous structure in the samples that have a crystallization time of $\leq 36 \mathrm{~h}$. To our knowledge, the isotherm of $\mathrm{C}-36 \mathrm{~h}$ (50) reported in our previous work was type I ascribed to the microporous structure (Xu et al 2010). Compared to 
the isotherm of C-36h (25) obtained from a high Al content with that of $\mathrm{C}-36 \mathrm{~h}$ (50) obtained from a low Al content (Xu et al 2010), results suggest that variation of Al content in the synthesis gel can affect the textural structure of the hierarchical porous aluminosilicate materials.

BJH pore size distribution calculated from the adsorption branches of C-16h (25), C-22h (25) and C-36h (25), is relatively narrow centred at $9.0,10 \cdot 1$ and $12.9 \mathrm{~nm}$, respectively
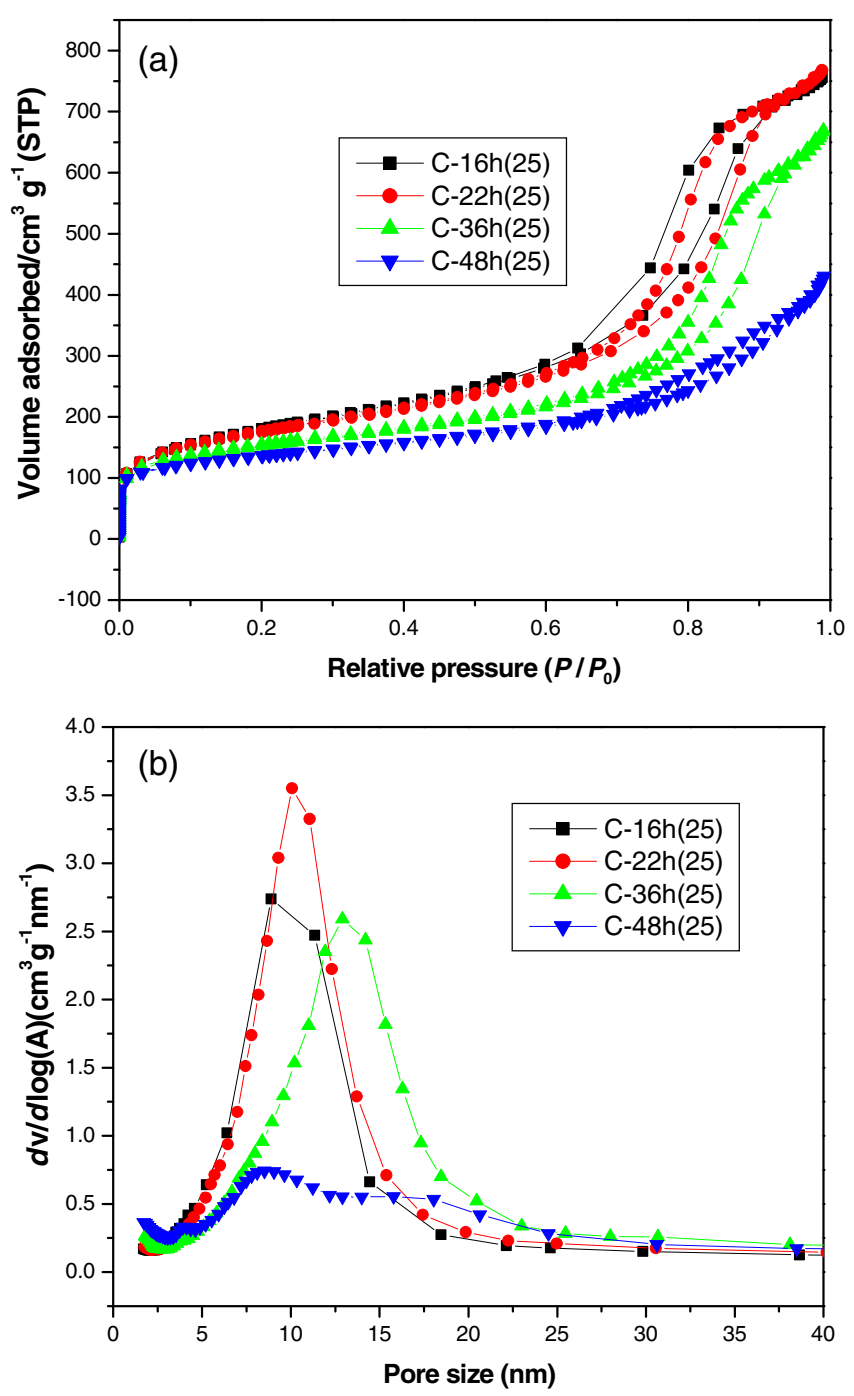

Figure 2. $\mathrm{N}_{2}$ adsorption-desorption isotherms (a) and pore size distribution (b) of hierarchical porous aluminosilicate materials. (figure 2(b)). However, pore size of C-48h (25) is broad, which indicates the intensive mesoporous structure gradually disappearing with the increased crystallization time.

The pore structural parameters of the hierarchical porous aluminosilicate materials are shown in table 1. BET surface area, microporous area and mesoporous area of the hierarchical porous materials $\mathrm{C}$-Xh (25) are all higher than those of $\mathrm{C}$-Xh (50) reported in our previous work with the same crystallization time (Xu et al 2010). For example, BET surface area and mesoprous area of C-36h (25) are 535 and $368 \mathrm{~m}^{2} / \mathrm{g}$, respectively which are larger than those of C-36h (50) reported in our preliminary work (382 and $105 \mathrm{~m}^{2} / \mathrm{g}$ ) (Xu et al 2010). This suggests that variation of $\mathrm{Al}$ content in the initial gel can alter the porous parameters of the hierarchical porous aluminosilicate materials. Increase of Al content in the synthesis gel offers the possibility of preparing the hierarchical porous materials with larger BET surface and mesoporous areas.

\subsection{SEM results}

SEM image can provide the macroporous structure of hierarchical porous materials. Figure 3 shows SEM images of the hierarchical porous aluminosilicate materials with $\mathrm{Si} / \mathrm{Al}$ molar ratio of 25 in the initial gel. As seen from figure 3, the macroporous structure of samples with a crystallization time of $\leq 22 \mathrm{~h}$ is spherical with an average diameter of $\mathrm{ca} 400 \mathrm{~nm}$. However, in the case of C-36h (25) and C-48h (25), framework of the macroporous structure is a cluster with the size of 1-3 $\mu \mathrm{m}$ formed by nanosized crystals. Moreover, it is hard to find any separated ZSM-5 crystals in SEM survey of C-36h (25) and C-48h (25), which is different from our previous report (Xu et al 2010). In our preliminary work, SEM image of C-36h (50) exhibited a separated ZSM-5 nanocrystal with the absence of a macroporous structure. Accordingly, SEM results suggest that an increased $\mathrm{Al}$ content in the initial gel favours the formation of a macroporous structure due to the lower crystallization rate and lack of formation of separated ZSM-5 nanocrystals.

\subsection{Element analysis and ${ }^{27}$ Al-MAS NMR studies}

The total Al content of the hierarchical porous aluminosilicate materials was determined by ICP measurements. $\mathrm{Si} / \mathrm{Al}$ molar ratio of the representative samples C-16h (25) and

Table 1. Pore structural parameters of hierarchical porous aluminosilicate materials.

\begin{tabular}{|c|c|c|c|c|c|c|c|}
\hline \multirow[b]{2}{*}{ Samples } & \multirow[b]{2}{*}{$\begin{array}{c}\mathrm{S}_{\mathrm{BET}} \\
\left(\mathrm{m}^{2} \mathrm{~g}^{-1}\right)\end{array}$} & \multicolumn{3}{|c|}{ Microporosity } & \multicolumn{3}{|c|}{ Mesoporosity } \\
\hline & & $\begin{array}{c}\text { Area } \\
\left(\mathrm{m}^{2} \mathrm{~g}^{-1}\right)\end{array}$ & $\begin{array}{l}\text { Size } \\
(\mathrm{nm})\end{array}$ & $\begin{array}{c}\text { Volume } \\
\left(\mathrm{cm}^{3} \mathrm{~g}^{-1}\right)\end{array}$ & $\begin{array}{c}\text { Area } \\
\left(\mathrm{m}^{2} \mathrm{~g}^{-1}\right)\end{array}$ & $\begin{array}{l}\text { Size } \\
(\mathrm{nm})\end{array}$ & $\begin{array}{c}\text { Volume } \\
\left(\mathrm{cm}^{3} \mathrm{~g}^{-1}\right)\end{array}$ \\
\hline C-16h (25) & 643 & 108 & 0.59 & $0 \cdot 04$ & 535 & $9 \cdot 0$ & $1 \cdot 15$ \\
\hline C-22h (25) & 624 & 128 & 0.57 & 0.05 & 496 & $10 \cdot 1$ & $1 \cdot 17$ \\
\hline C-36h (25) & 535 & 167 & 0.53 & 0.07 & 368 & $12 \cdot 9$ & 1.01 \\
\hline C-48h (25) & 472 & 191 & 0.49 & 0.08 & 281 & $8 \cdot 4$ & $0 \cdot 64$ \\
\hline
\end{tabular}



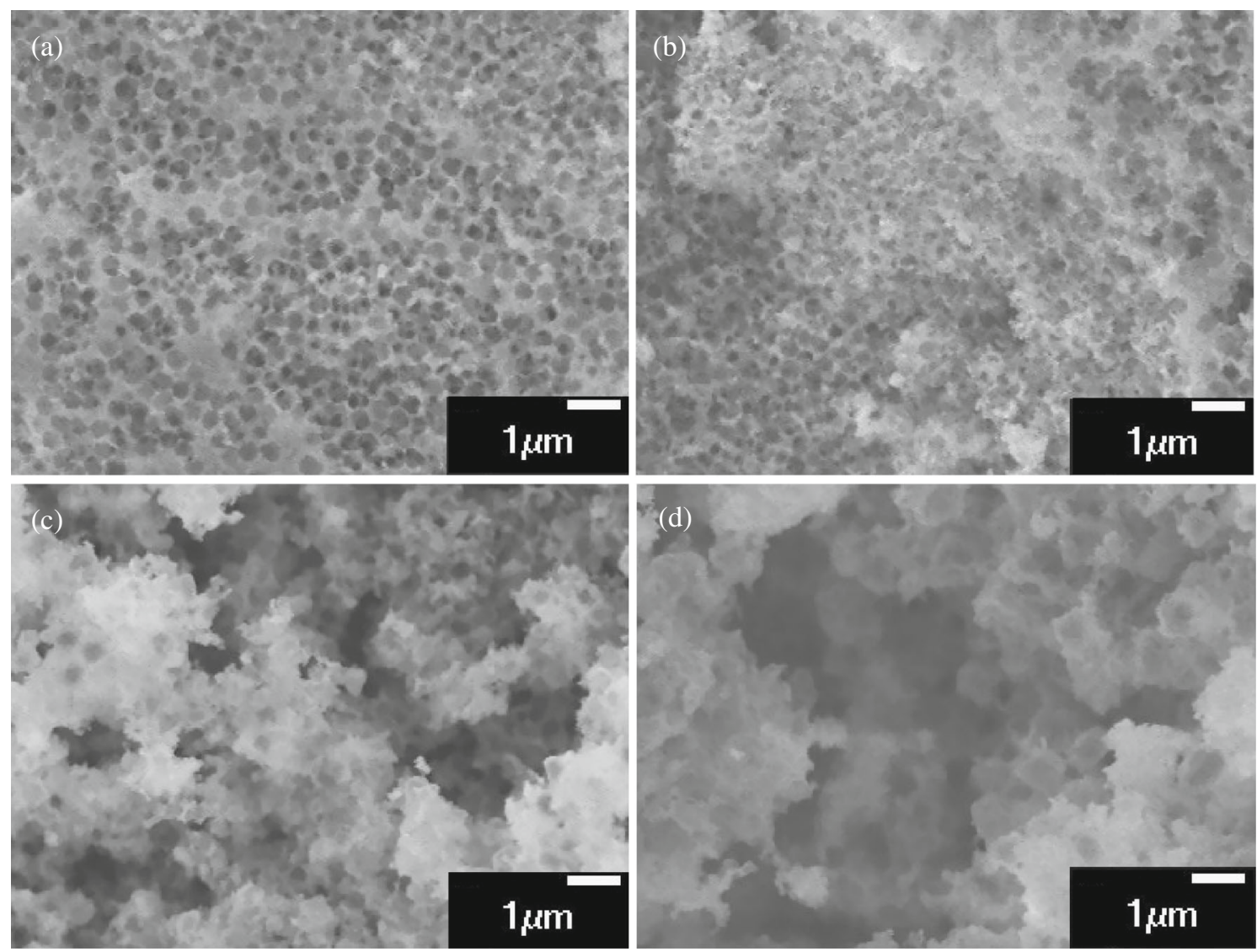

Figure 3. SEM images of samples: (a) C-16h (25), (b) C-22h (25), (c) C-36h (25) and (d) C-48h (25).

$\mathrm{C}-36 \mathrm{~h}$ (25) is 29.3 and 28.4 , respectively which is close to $\mathrm{Si} / \mathrm{Al}$ molar ratio of the initial synthesis gel $\left(n_{\mathrm{Si}} / n_{\mathrm{Al}}=25\right)$.

${ }^{27}$ Al-MAS NMR spectra were collected from the selective samples C-16h (25) and C-36h (25) in order to investigate the effect of increasing $\mathrm{Al}$ content in the initial gel on $\mathrm{Al}$ atoms in the framework. Figure 4 depicts ${ }^{27} \mathrm{Al}-\mathrm{MAS}$ NMR spectra of the representative hierarchical porous aluminosilicate materials. A strong peak is observed at $c a 50 \mathrm{ppm}$, indicating the presence of tetrahedrally coordinated $\mathrm{Al}$ in the framework of the hierarchical porous aluminosilicate materials. However, the octahedrally coordinated $\mathrm{Al}$ is almost negligible, as demonstrated by the absence of a characteristic peak at around $0 \mathrm{ppm}$. This result implies that $\mathrm{Al}$ atom in the initial gel has been incorporated into the framework of the hierarchical porous aluminosilicate materials and formed more acidic sites due to the increased $\mathrm{Al}$ content in the framework.

\subsection{Catalytic results}

Hierarchical porous system and higher Al content in the framework of the hierarchical porous aluminosilicate materials confirmed by the results should make them suitable for acidic catalysis applications involving large molecules. Therefore, the hierarchical porous aluminosilicate materials were tested as catalysts in the alkylation of phenol with tert-butanol. Phenol alkylation with tert-butyl alcohol is a

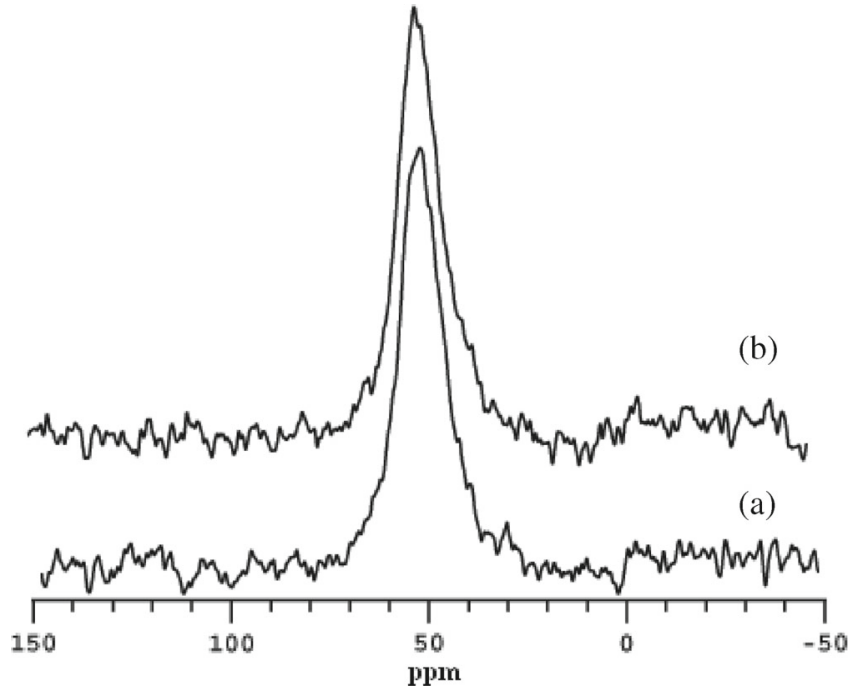

Figure 4. ${ }^{27} \mathrm{Al}-\mathrm{MAS}$ NMR spectra of representative samples: (a) C-16h (25) and (b) C-36h (25).

typical acid catalysis reaction (Sato et al 2001; Anand et al 2003). In the present study, the reaction products contain 2-tert-butyl phenol (2-TBP), 4-tert-butyl phenol (4-TBP), 2,4-di-tert-butyl phenol (2,4-di-TBP) and a small amount of 2,4,6-tri-tert-butyl phenol (2,4,6-tri-TBP). Different pore 
Table 2. Catalytic activity and product distribution. ${ }^{\mathrm{a}}$

\begin{tabular}{lccccc}
\hline & & \multicolumn{4}{c}{ Selectivity (\%) } \\
\cline { 3 - 6 } Catalysts & Conversion (\%) & 2-TBP & 4-TBP & 2,4-di-TBP & 2,4,6-tri-TBP \\
\hline C-16h (25) & $93 \cdot 2$ & $3 \cdot 8$ & $43 \cdot 9$ & $50 \cdot 7$ & $1 \cdot 6$ \\
C-22h (25) & $92 \cdot 0$ & $3 \cdot 9$ & $48 \cdot 2$ & $46 \cdot 6$ & $1 \cdot 3$ \\
C-36h (25) & $91 \cdot 0$ & $3 \cdot 9$ & $48 \cdot 9$ & $45 \cdot 9$ & $1 \cdot 3$ \\
C-48h (25) & $90 \cdot 7$ & 4.7 & $49 \cdot 3$ & $45 \cdot 0$ & 1.0 \\
\hline
\end{tabular}

${ }^{\text {a }}$ Reaction temperature $=418 \mathrm{~K}$; Phenol:TBA $=1: 2.5$ (molar ratio); WHSV $=2 \cdot 20 \mathrm{~h}^{-1}$; TBP corresponding to tert-butyl phenol. Products were withdrawn and quantified after reaction was on for $2 \mathrm{~h}$.

structures and acidities of the catalyst can lead to different catalytic activity and distribution of products (Zhang et al 1998). The larger pore size and stronger acidity of a catalyst are favoured to improve the catalytic activity and the selectivity to major product, 2,4-di-TBP.

The results of phenol alkylation with tert-butyl alcohol over the hierarchical porous aluminosilicate catalysts are listed in table 2. The phenol conversion and the selectivity to major product 2,4-di-TBP over the hierarchical porous aluminosilicate catalysts with $n_{\mathrm{Si}} / n_{\mathrm{Al}}=25$ exceed 90 and $45 \%$, respectively which is higher than those over the hierarchical porous aluminosilicate catalysts with $n_{\mathrm{Si}} / n_{\mathrm{Al}}=50$ in the initial gel (Xu et al 2010). This phenomenon can be explained as follows: since the amount of $\mathrm{Al}$ atoms in the hierarchical porous aluminosilicate catalysts with $n_{\mathrm{Si}} / n_{\mathrm{Al}}=$ 50 is relatively small, the acidity is weak, which leads to a relatively low catalytic activity and selectivity of 2,4-di-TBP. Compared with the hierarchical porous aluminosilicate catalysts with $n_{\mathrm{Si}} / n_{\mathrm{Al}}=50$, more $\mathrm{Al}$ atoms are incorporated into the silica framework of the hierarchical porous aluminosilicate materials with $n_{\mathrm{Si}} / n_{\mathrm{Al}}=25$ and formed a stronger acidity confirmed by element analysis and ${ }^{27} \mathrm{Al}-\mathrm{MAS}$ NMR results. Thus, their catalytic performance is obviously higher than those over the catalysts with $n_{\mathrm{Si}} / n_{\mathrm{Al}}=50$.

\section{Conclusions}

The hierarchical porous aluminosilicate materials were prepared successfully using polystyrene spheres as hard templates. Effect of increased Al content in the initial gel on the textural properties and catalytic activity were also studied. The results showed that crystallization rate of the macorporous wall decreased and the macroporous structures of the hierarchical porous aluminosilicate materials were maintained with increased $\mathrm{Al}$ content in the initial gel. Furthermore, the hierarchical porous aluminosilicate catalysts exhibited higher catalytic activity due to a stronger acidity derived from the increased $\mathrm{Al}$ content in the framework.

\section{Acknowledgements}

We acknowledge the Natural Science Foundation of Inner Mongolia (2011BS0203), the Program for Young Talents of Science and Technology in Universities of Inner Mongolia Autonomous Region (NJYT-12-B17) and financial support of the National Natural Science Foundation of China (No. 21061010).

\section{References}

Ali M A, Brisdon B and Thomas W J 2003 Appl. Catal. A252 149

Anand R, Maheswari R, Gore K and Tope B 2003 J. Mol. Catal. A193 251

Holma M S, Taarning E, Egeblad K and Christensen C H 2011 Catal. Today 1683

Huang Y, Wang K, Dong D, Li D, Hill M R, Hill A J and Wang H 2010 Micropor. Mesopor. Mater. 127167

Lei Q, Zhao T, Li F, Zhang L and Wang Y 2006 Chem. Commun. 161769

Persson A, Schoeman B, Sterte J and Otterstedt J E 1995 Zeolites 15611

Sato T, Sekiguchi G, Adschiri T and Arai K 2001 Chem. Commun. 171566

Serrano D P, García R A, Vicente G, Linares M, Procházková D and Čejka J 2011 J. Catal. 279366

Shetti V N, Kim J, Srivastava R, Choi M and Ryoo R 2008 J. Catal. 254296

Song T, Liu L and Xu R 1991 Chinese J. Catal. 12281

Sun Y and Prins R 2008 Appl. Catal. A: General 33611

Takahashi R, Sato S, Sodesawa T and Yabuki M 2001 J. Catal. 200 197

Valtchev V 2002 J. Mater. Chem. 121914

Wang Y, Tang Y, Ni Z, Hua W, Yang W, Wang X, Tao W and Gao Z 2000 Chem. Lett. 29510

Xu L, Ma Y, Ding W, Guan J, Wu S and Kan Q 2010 Mater. Res. Bull. 451293

Yuan Z Y and Su B L 2006 J. Mater. Chem. 16663

Zhang K, Huang C, Zhang H, Xiang S, Liu S, Xu D and Li H 1998 Appl. Catal. A: General 16689

Zhu G et al 2001 J. Mater. Chem. 111687 